\title{
The satiety effect of disguised liquid preloads administered acutely and differing only in their nutrient content tended to be weaker for lipids but did not differ between proteins and carbohydrates in human subjects
}

\author{
Mylène Potier ${ }^{1}$, Gilles Fromentin ${ }^{1,2}$, Aurélie Lesdema ${ }^{1,2}$, Robert Benamouzig ${ }^{3}$, Daniel Tomé ${ }^{1,2}$ \\ and Agnès Marsset-Baglieri ${ }^{1,2 *}$ \\ ${ }^{1}$ INRA, CNRH-IdF, UMR 914 Nutrition Physiology and Ingestive Behavior, F-75005 Paris, France \\ ${ }^{2}$ AgroParisTech, CNRH-IdF, UMR 914 Nutrition Physiology and Ingestive Behavior, F-75005 Paris, France \\ ${ }^{3}$ Department of Gastroenterology, Avicenne Hospital, Assistance Publique-Hôpitaux de Paris, Clinical Investigation \\ Centre of CRNH Ile-de-France (Human Nutrition Research Centre), 93000 Bobigny, France
}

(Received 29 July 2009 - Revised 24 March 2010 - Accepted 25 March 2010 - First published online 17 June 2010)

Whether protein is the macronutrient with the strongest satiety effect remains a matter of debate because of the diversity of study designs employed. The aim of the present study was to compare the effect of different liquid preloads made up of proteins, fats or carbohydrates only, under stringently controlled conditions, on satiety. Fifty-six subjects participated in the present study which consisted of four randomised test days, i.e. $1 \mathrm{~d}$ per macronutrient and one control day. During each test day, the subjects were required to consume the preload in full, and then their subsequent food intake was measured. The volunteers were divided into two groups: the first (T0) group, which consumed the preload immediately before lunch, and the second (T1) group, which consumed it $1 \mathrm{~h}$ beforehand. The main results showed that the participants consumed significantly less at lunch following the consumption of all three preloads than on the no-preload day, and consumed less after the consumption of the carbohydrate preload than after the consumption of the lipid preload. When energy from the preload was included, overall energy intake was significantly greater in all the three preload conditions than in the situation involving no preload, with only partial compensation for preload energy in all conditions. Total daily energy intake was highest after the lipid preload ingestion, but this could be a chance finding since it was not significantly higher than that observed after protein or carbohydrate preload ingestion. No significant effects of the interval between the preload and test meal ingestion were found. These results do not confirm the greater satiety effect of proteins than of carbohydrates, but partially confirm the weaker effect of fats.

Satiety: Macronutrients: Liquid preloads

Numerous studies have supported the idea of a hierarchy in the satiety effect of macronutrients ${ }^{(1-4)}$. Proteins are believed to be the macronutrients with the strongest satiety effect in rats and human subjects ${ }^{(3,5-13)}$, followed by carbohydrates and lipids. Indeed, Porrini et al. ${ }^{(14)}$ showed that in healthy men, energy intake at an ad libitum test meal was lower after the ingestion of a protein preload (omelette containing $53.5 \%$ of energy supplied by proteins) than after the ingestion of a lipid preload (omelette containing $79.3 \%$ of energy supplied by lipids). Moreover, Bertenshaw et al. ${ }^{(5)}$ demonstrated that healthy men were less hungry and had a lower food intake after ingesting a high-protein drink $(50 \%$ of proteins and $50 \%$ of carbohydrates) than after ingesting a high-carbohydrate one $(97.6 \%$ of carbohydrates and $2.4 \%$ of proteins). However, some studies are not in agreement with this hierarchy of satiety effect of macronutrients ${ }^{(15-18)}$.
Indeed, Rolls et al. ${ }^{(17)}$ showed that a high-carbohydrate yoghourt ( $81 \%$ of carbohydrates) and a high-fat one did not differentially impact food intake at test meal, and Capaldi et al. ${ }^{(18)}$ showed that food intake $40 \mathrm{~min}$ after the ingestion of a high-carbohydrate preload was not different from food intake after the ingestion of a high-protein one.

The discrepancies between these findings probably come from many other food properties that may influence appetite sensations and food intake in addition to the macronutrient content, such as energy density, texture and sensory properties, as well as from the knowledge and beliefs regarding the food being tested. Several studies have shown that food with a low energy density would be more satiating than food with a high energy density ${ }^{(19,20)}$. In his review, Poppitt et $a l .{ }^{(20)}$ showed that, independently of their lipid content, foods with a low energy density have a higher satiety effect

Abbreviations: T0, group of volunteers who ate their lunch immediately after ingesting the preload; T1, group of volunteers who ate their lunch $1 \mathrm{~h}$ after ingesting the preload; VAS, visual analogue scales.

* Corresponding author: A. Marsset-Baglieri, fax +331440818 58, email agnes.marsset-baglieri@agroparistech.fr 
than those with a high energy density, suggesting that the weight and volume of food consumed were important parameters that are to be taken into account in food behaviour studies. Results regarding the influence of the texture of food are sometimes controversial. Mattes \& Rothacker ${ }^{(21)}$ concluded that a viscous drink leads to a higher decrease of hunger sensations than a low-viscosity isopalatable drink with the same energy density and macronutrient content. Moreover, some studies reported that liquids fail to trigger physiological satiety mechanisms, so that compensation for energy consumed as beverages may be imprecise and incomplete $^{(22,23)}$. However, the evidence that liquids have less impact on satiety than solid foods remains inconclusive. Indeed, Bertenshaw et al. ${ }^{(5)}$ showed that the consumption of a high-protein beverage but not of a high-carbohydrate one was partially compensated, showing that satiety effect of liquid foods also depended on their macronutrient composition, particularly on the protein content.

The time between the ingestion of the preload and the ad libitum test meal also seems to be an important parameter that has to be considered while assessing the energy intake at test meal. In some studies, the test meal is consumed immediately after preload ingestion ${ }^{(14,24,25)}$, after a quite short delay (between $30 \mathrm{~min}$ and $2 \mathrm{~h})^{(5,16,18)}$ or after more than $3 \mathrm{~h}^{(26,27)}$. A very short delay may involve only oro-sensitive and gastric pre-absorptive signals since the first post-absorptive signals appear about $20 \mathrm{~min}^{(25)}$ after the start of the meal, while post-absorptive signals would be involved in case of a long delay between the preload and test meal ingestion. Some studies have compared the effects of different delays between the preload and test meal ingestion ${ }^{(14,28)}$. Anderson et al. ${ }^{(28)}$ reported that the consumption of a liquid preload containing about $50 \mathrm{~g}$ of protein led to a decrease in subsequent energy intake with a delay of $1 \mathrm{~h}$ between the preload and test meal ingestion, but this satiety effect of proteins disappeared with a delay of $2 \mathrm{~h}$. Porrini et al. ${ }^{(14)}$ obtained the same result with solid high-protein preloads served immediately or $2 \mathrm{~h}$ before the test meal. Moreover, the time elapsing between the preload and test meal ingestion also seems to be particularly important when solid and liquid preloads are compared. Indeed, Almiron-Roig et al. $^{(29)}$ reported that studies which demonstrated greater satiating power of solids over liquids generally used a long time delay between the preload and test meal ingestion (between 2 and $4 \mathrm{~h}$ ). In contrast, studies which showed that liquids are more satiating than solid foods used a very short time delay between the preload and test meal ingestion $(<30 \mathrm{~min})$. It is apparent that energy compensation following the ingestion of liquid preloads occurs when the interval between ingestion of the preload and test meal is small, whereas the reverse is observed for solid foods ${ }^{(23,30-33)}$.

In the literature, just a few studies really focus only on the effect of macronutrient composition on satiety. Most studies that explored the effect of macronutrients on satiety and food intake did not use preloads with the same energy content, the same energy density and the same level of palatability. The objective of the present study was therefore to measure the effects of proteins, carbohydrates and lipids on food intake and appetite scores using disguised preloads containing only one of the three macronutrients, but with the same volume, energy content, energy density, viscosity and palatability.

\section{Subjects and methods}

This study was done at the Laboratory of Sensory Perception and Sensometry of AgroParisTech (Massy, France). This study was conducted according to the guidelines laid down in the Declaration of Helsinki, and all procedures involving human subjects were approved by the Comité de Protection des Personnes Ile de France X (Aulnay-sous-Bois, France). Written informed consent was obtained from all the subjects.

\section{Subjects}

Sixty volunteers were recruited by means of posters and messages sent to electronic mailing lists. All the subjects were healthy non-smokers, aged from 18 to 60 years, with a BMI ranging from 18 to $25 \mathrm{~kg} / \mathrm{m}^{2}$. They did not display any food allergies or dislikes regarding the foods proposed for the test meals and preloads, and were not taking any medication known to affect appetite. Moreover, we only recruited volunteers who, in response to a general food habits questionnaire, stated that they were used to eating three regular meals per day. Pregnant or breast-feeding women, athletes in training, people with a score $>10$ on the restraint subscale of the Three-Factor Eating Questionnaire ${ }^{(34)}$ and those suffering from hypercholesterolaemia or diabetes were excluded from the study (information solicited by means of questionnaires and interview with experimenters). The subjects received financial compensation for their participation, and the true nature of the study was revealed to them during a debriefing session once it had been completed. Of the sixty subjects recruited, four did not complete the protocol (preloads not entirely consumed and problems of compliance with the schedules). As a consequence, the final sample consisted of twelve men and forty-four women with a mean BMI of 21.0 (SEM 1.7$) \mathrm{kg} / \mathrm{m}^{2}$, and a mean age of 31.2 (SEM 12.2) years. The debriefing discussion revealed that the volunteers had not realised that food consumption and the effects of a preload on appetite were the focus of the study.

\section{Menus and foods}

All the foods were widely available, industrial products. Before the study was started, we ensured that volunteers liked the different foods proposed in order to reduce lassitude and dislikes. The subjects were provided with a wide variety of the foods that make up a typical French breakfast, plus biscuits and an apple sauce portion for an optional afternoon snack, and a full menu for dinner. The breakfast, afternoon snack and dinner were supplied in ready-packed containers which the volunteers ate freely at home. The subjects were required to consume the breakfast provided for each test day in full, so that they would arrive at the laboratory in the same state of appetite. Compliance was determined by asking the subjects to return the empty containers. The energy content of the breakfast was adapted to the sex of the volunteers: $2161.9 \mathrm{~kJ}$ for men and $1920.4 \mathrm{~kJ}$ for women. Lunch was served at the laboratory in private cubicles, and comprised a full menu with a main course and dessert. All foods (Table 1) were served in generous portions that were 
Table 1. Energy content of foods served to the subjects

\begin{tabular}{lc}
\hline & Energy of the portion $(\mathrm{kJ})$ \\
\hline Breakfast & \\
Orange juice $(200 \mathrm{ml})$ & $360 \cdot 2$ \\
Bread & $725 \cdot 2$ \\
$60 \mathrm{~g}$ for men & $483 \cdot 7$ \\
$40 \mathrm{~g}$ for women & $340 \cdot 1$ \\
Jam $(30 \mathrm{~g})$ & $308 \cdot 5$ \\
Butter $(10 \mathrm{~g})$ & $427 \cdot 9$ \\
Yoghourt $(125 \mathrm{~g})$ & 0 \\
Sweetener $(2 \mathrm{~g})$ & \\
Lunch & $2180 \cdot 0$ \\
Moussaka $(500 \mathrm{~g})$ & $967 \cdot 2$ \\
Fresh cheese $(300 \mathrm{~g})$ & $845 \cdot 4$ \\
Fruit salad $(300 \mathrm{~g})$ & $120 \cdot 0$ \\
Powdered sugar $(30 \mathrm{~g})$ & \\
Afternoon snack & $928 \cdot 7$ \\
Biscuits $(50 \mathrm{~g})$ & $221 \cdot 5$ \\
Apple sauce $(90 \mathrm{~g})$ & \\
Dinner & $3308 \cdot 4$ \\
Chicken and vegetable dish $(900 \mathrm{~g})$ & $1801 \cdot 6$ \\
Cheese $(125 \mathrm{~g})$ & $1602 \cdot 6$ \\
Vanilla cream $(300 \mathrm{~g})$ & \\
\hline
\end{tabular}

weighed before being served and then reweighed after the subjects had eaten, so as to obtain the net amount consumed of each food. The subjects were asked to return any uneaten foods from their packed meals on the day after each test day.

\section{Preloads}

The three preloads used in this study were hot chocolate drinks of $250 \mathrm{ml}$ containing either proteins only, carbohydrates only or lipids only (Table 2). The drinks were isoenergetic (about $1025 \mathrm{~kJ}$ ), were prepared in the laboratory on each test day and were served with a straw in an opaque cup. A pilot study, involving sixty-two volunteers who did not participate in the main study, was conducted to determine whether the palatability of the three preloads was similar. The sixty-two volunteers had to taste $10 \mathrm{ml}$ of each preload and to evaluate its palatability using a questionnaire that proposed nine degrees of pleasantness from 'extremely unpleasant' to 'extremely pleasant'. The scores obtained for protein, carbohydrate and lipid preloads were not statistically different (4.08 (SEM 0.21), 4.58 (SEM 0.21) and 3.95 (SEM $0 \cdot 23$ ), respectively). The palatability of the three preloads was measured on each test day by the volunteers of the main study too.

\section{Design}

The volunteers were divided into two groups, defined as a function of the time elapsing between consumption of the preload and lunch: in group T0, there was no delay, but in group $\mathrm{T} 1$, a $1 \mathrm{~h}$ interval was allowed. The two groups had the same sex balance (six men and twenty-two women), and had similar average BMI (21.1 (SEM 1.9) and 21.0 (SEM 1.7) kg/m $\mathrm{m}^{2}$ in groups T1 and T0, respectively). Within the same group, each volunteer was tested on four randomised days: a control day without a preload, a day with the protein drink, a day with the carbohydrate drink and a day with the lipid drink. The four test days were separated by an interval of 1 week. On each test day, the subjects were instructed to eat all the breakfast provided for them at home between 7.00 and 8.30 hours, and were not allowed to consume any foods or energycontaining beverages until they arrived at the laboratory: at 11.30 hours for the subjects in group $\mathrm{T} 1$ and at 12.30 hours for the subjects in group T0. At arrival to the laboratory, each subject was taken to a private cubicle and asked to eat the entire preload within $15 \mathrm{~min}$, except on the control day when s/he was asked to look through magazines devoid of any references to food. For group T0, the ad libitum lunch was served immediately after the volunteers had consumed the preload, while for group $\mathrm{T} 1$, lunch was served $1 \mathrm{~h}$ later. The subjects were asked to eat this lunch within $45 \mathrm{~min}$. They then left the laboratory having been supplied with food for their afternoon snack and dinner, and were not allowed to consume any energetic beverages for the rest of the day (Fig. 1).

\section{Visual analogue scales}

The subjects were asked to indicate, on a scale from 0 to $100 \mathrm{~mm}$, how they felt at the moment they completed the following questions: How hungry do you feel now? (not hungry at all-extremely hungry); How full do you feel now? (not full at all-extremely full); How strong is your desire to eat now? (very weak-very strong); How much food do you think you could eat now? (nothing at all-a large amount); How nauseous do you feel now? (not nauseous at all-extremely nauseous). These visual analogue scales (VAS) were completed after breakfast, immediately before and after consumption of the preload (or at the corresponding hours during the control day), at 12.00 hours, before and after lunch, at 14.00, 15.00, 17.00, 19.00 hours, and before and after dinner. The palatability of meals (lunch and dinner) was also measured using VAS.

Table 2. Composition and energy content of the three preloads

\begin{tabular}{llcc}
\hline & Protein preload & Carbohydrate preload & Lipid preload \\
\hline Energy density $(\mathrm{kJ} / 100 \mathrm{~g})$ & $415 \cdot 8$ & 394.4 & 436.9 \\
Energy of a drink $(\mathrm{kJ})$ & 1019.1 & 1029.1 & $1016 \cdot 2$ \\
Ingredients $(\mathrm{g} / 250 \mathrm{ml})$ & $50 \mathrm{~g}$ of proteins: & $50 \mathrm{~g}$ of maltodextrins & $22.3 \mathrm{~g}$ of oil: \\
& $90 \%$ of whey proteins & & $50 \%$ palm oil \\
& $10 \%$ of casein & & $50 \%$ soya bean oil \\
& $150 \mathrm{~g}$ of water & $180 \mathrm{~g}$ of water & $180 \mathrm{~g}$ of water \\
& $11.25 \mathrm{~g}$ of aroma & $11.25 \mathrm{~g}$ of aroma & $11.25 \mathrm{~g}$ of aroma \\
& $2.5 \mathrm{~g}$ of sweetener & $2.5 \mathrm{~g}$ of sweetener & $3.75 \mathrm{~g}$ of sweetener \\
\hline
\end{tabular}


T1 group
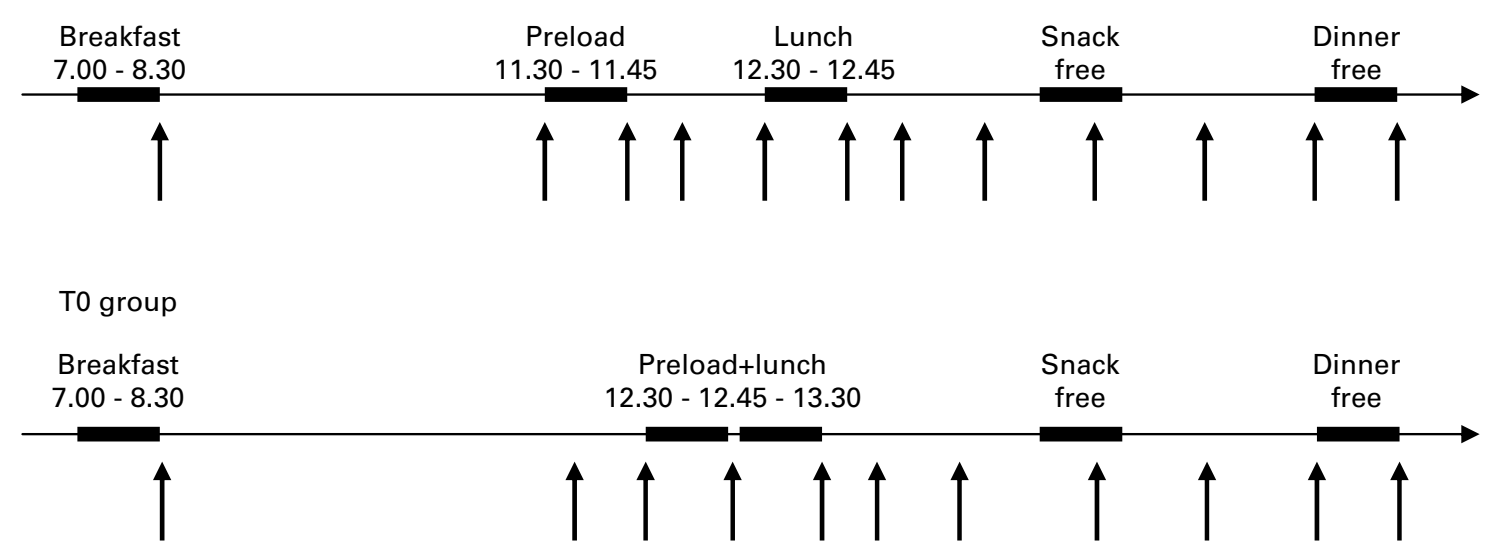

Fig. 1. Experimental design of a test day for groups $\mathrm{T} 1$ (group of volunteers who ate their lunch $1 \mathrm{~h}$ after ingesting the preload) and T0 (group, which consumed the preload immediately before lunch). $\uparrow$, Visual analogue scales.

\section{Statistical analyses}

Statistical analyses were performed using SAS for Windows (version 9.1; SAS Institute, Inc., Cary, NC, USA). Descriptive data are presented as means with their standard errors. Results were considered to be significant at the level of $P<0.05$. A 2 (preload times) $\times 4$ (preload conditions) ANOVA was performed to study energy intake and energy compensation values. Tukey's significant difference test was used for post hoc comparisons of general significant effects. Energy intake at lunch and the $24 \mathrm{~h}$ food intake with and without the preload were analysed. The percentage of energy compensation at lunch for preload $\mathrm{P}$ was calculated as follows:

$$
\begin{aligned}
& \text { Energy compensation at lunch } \\
& \begin{array}{l}
=100 \times(\text { energy consumed at control lunch } \\
- \text { energy consumed at lunch after preload } \\
\quad \mathrm{P} \text { ingestion }) / \text { energy of preload } \mathrm{P} \text {. }
\end{array}
\end{aligned}
$$

In the same way, the percentage of energy compensation over the whole day was calculated by dividing the difference in $24 \mathrm{~h}$ energy intake between the control situation and situation $\mathrm{P}$ by the energy value of the preload $\mathrm{P}$ :

- if compensation is statistically $<0 \%$, then it is null compensation;

- if compensation is statistically $>0 \%$ and statistically $<100 \%$, then it is partial compensation;
- if compensation is statistically $>0 \%$ and does not differ from $100 \%$, then it is complete or full compensation;

- if compensation is statistically $>100 \%$, then it is overcompensation.

Difference from 0 to $100 \%$ was analysed using the Student tests (H0: compensation $=0 \%$, and then H0: compensation $=0 \%)$.

A one-way ANOVA was performed to analyse the palatability of the three preloads. Tukey's significant difference test was used for post hoc comparisons of general significant effects.

Finally, rating data were studied by an ANOVA for repeated measures in each group. The Tukey-Kramer significant difference test was used for post hoc comparisons of general significant effects.

\section{Results}

\section{Palatability of preloads and meals}

In both groups, there was no difference in palatability between the three preloads (scores: $5 \cdot 1$ (SEM 0.2) for the protein preload; 5.5 (SEM 0.2) for the carbohydrate preload and 5.7 (SEM 0.3) for the lipid preload). Lunch and dinner were considered to be isopalatable, with respective mean scores of 69.9 (SEM 2.0) and 70.5 (SEM 1.8) mm on the VAS. Consuming a preload did not modify the palatability of lunch and dinner when compared with the control conditions, and the palatability of these two meals did not differ as a function

\begin{tabular}{|c|c|c|c|c|c|c|c|c|}
\hline & \multicolumn{2}{|c|}{ Control } & \multicolumn{2}{|c|}{ Proteins } & \multicolumn{2}{|c|}{ Carbohydrates } & \multicolumn{2}{|c|}{ Lipids } \\
\hline & Mean & SEM & Mean & SEM & Mean & SEM & Mean & SEM \\
\hline Lunch & $2907 \cdot 7^{a}$ & $106 \cdot 0$ & $2478 \cdot 2^{b, c}$ & $116 \cdot 3$ & $2346 \cdot 3^{c}$ & $120 \cdot 2$ & $2559.4^{b}$ & $150 \cdot 0$ \\
\hline Lunch + preload & $2907 \cdot 7^{b}$ & $106 \cdot 0$ & $3497 \cdot 2^{a}$ & $116 \cdot 3$ & $3375 \cdot 4^{\mathrm{a}}$ & $120 \cdot 2$ & $3575 \cdot 6^{a}$ & $150 \cdot 0$ \\
\hline Meals & $9726 \cdot 8^{\mathrm{a}}$ & 297.0 & $9026 \cdot 6^{\mathrm{b}}$ & $315 \cdot 7$ & $8928.9^{b}$ & 322.5 & $9179 \cdot 1^{\mathrm{b}}$ & $343 \cdot 0$ \\
\hline Meals + preload & $9726 \cdot 8^{\mathrm{b}}$ & 297.0 & $10038 \cdot 5^{a, b}$ & $116 \cdot 3$ & $9958 \cdot 0^{a, b}$ & 322.5 & $10183 \cdot 5^{\mathrm{a}}$ & $343 \cdot 0$ \\
\hline
\end{tabular}
of the preload ingested.

Table 3. Energy intake (kJ) at lunch and over the $24 \mathrm{~h}$ period (Mean values with their standard errors)

${ }^{\mathrm{a}, \mathrm{b}}$ Mean values within a column with unlike superscript letters were significantly different $(P<0.05)$. 


\section{Energy intake}

At lunch, analysis of the effect of the time elapsing between the preload and test meal ingestion showed that there was no significant difference between groups $\mathrm{T} 0$ and $\mathrm{T} 1$, and that there was no group $\times$ preload interaction. The ingestion of a preload led to a decrease in food intake at lunch compared with the control $(F(3,162)=11.79, P<0.0001)$. Indeed, energy intake following the ingestion of proteins, carbohydrates and lipids was lower than the control energy intake $(P=0.0001,<0.0001$ and 0.0004 , respectively). Moreover, energy intake at lunch was lower after carbohydrate ingestion than after lipid ingestion $(P=0.041)$. When the energy value of the preloads was added to the energy consumed at lunch, energy intake was significantly higher following the ingestion of a preload compared with the control $(F(3,162)=18 \cdot 28$, $P<0.0001)$. There was no significant difference between the three preloads (Table 3 ).

Throughout the day (breakfast, lunch, afternoon snack and dinner), analysis of the effect of the time elapsing between the preload and test meal ingestion showed that there was no significant difference between groups T0 and T1, and that there was no group $\times$ preload interaction. The ingestion of a preload led to a decrease in daily food intake compared with the control $(F(3,162)=8.48, \quad P<0.0001)$. Indeed, energy intake following the ingestion of proteins, carbohydrates and lipids was lower than the control energy intake $(P<0.0001,<0.0001$ and 0.0018 , respectively). Overall, daily energy intake (i.e. the total of all meals and the preload) was significantly higher on the day the lipid preload was consumed than on the no-preload control day $(P=0.0093)$, but overall energy intake on the days the protein and carbohydrate preloads were consumed was intermediate between intake on the lipid and control days, and did not differ significantly from either of these. There was no difference between the three preloads (Table 3).

As for energy compensation, the volunteers partially compensated for the energy supplied by the preloads at lunch (42.3 (SEM 8.5), 53.2 (SEM 7.4) and 36.1 (SEM 11.1)\%, respectively, with the protein, carbohydrate and lipid preloads). Energy compensation values at lunch were not different between the three preloads. Over the whole day, energy compensation was not different from $100 \%$ with the carbohydrate preload (77.5 (SEM 16.0)\%) and was partial with the protein and lipid preloads (69.2 (SEM 15.4) and 56.3 (SEM 18.5)\%, respectively), although these values did not differ significantly between the preloads.

\section{Visual analogue scales scores}

In group T0, when the effect of ingesting the preloads was compared with the control, differences were only observed just before lunch. Hunger and prospective consumption decreased significantly with the protein preload $(P=0.02$ and $0 \cdot 03$, respectively) and the lipid preload $(P=0.001$ and $0 \cdot 01$, respectively) but not with the carbohydrate preload, when compared with the control. Desire to eat only decreased significantly with the lipid preload $(P=0.001)$, while fullness increased significantly with all the three preloads $(P=0 \cdot 01$, 0.001 and 0.01 with proteins, carbohydrates and lipids, respectively) compared with the control. These differences
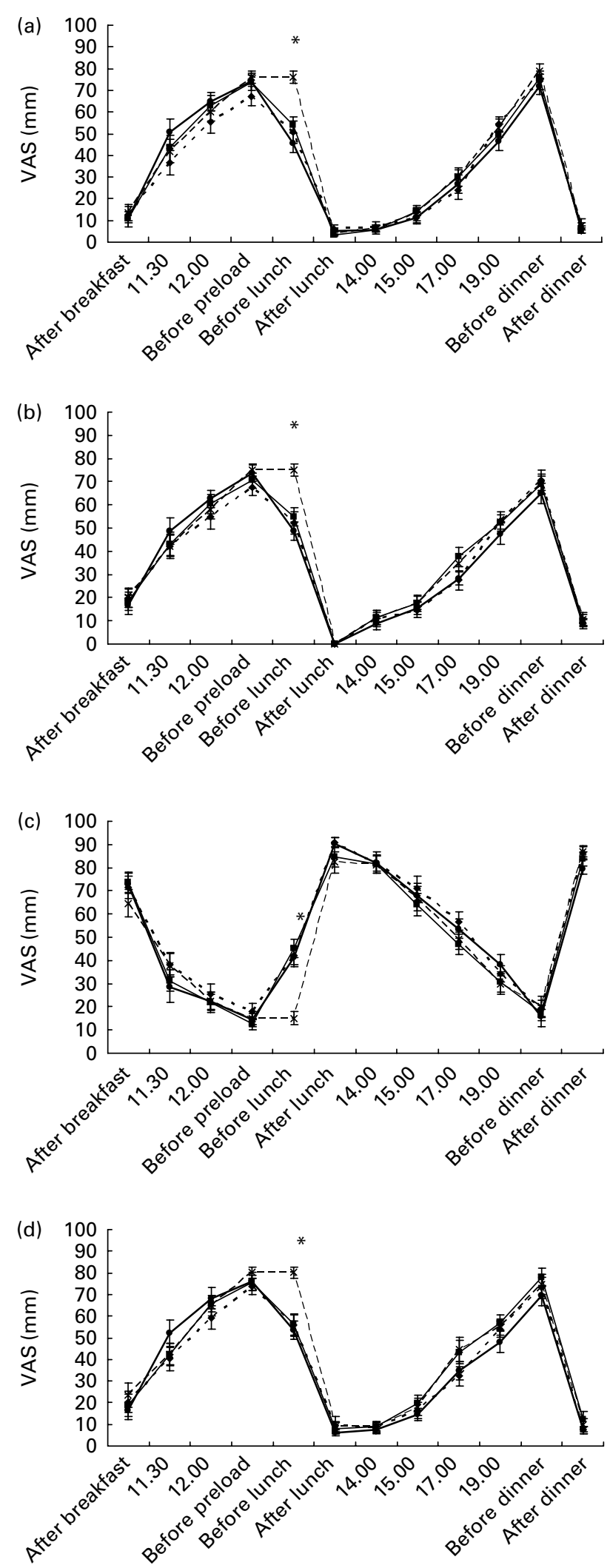

Fig. 2. (a) Hunger, (b) prospective food consumption, (c) fullness and (d) desire to eat scores rated by visual analogue scales (VAS) throughout the day in group TO (group of volunteers who ate their lunch immediately after ingesting the preload, $n$ 28). Values are means ( $\mathrm{mm}$ ) with their standard errors. * Mean VAS scores were significantly different from the control with at least one of the three preloads $(P<0.05)$. $-\bullet-$, Protein; - —-, carbohydrates; - - - lipids; $-\times-$, control. 


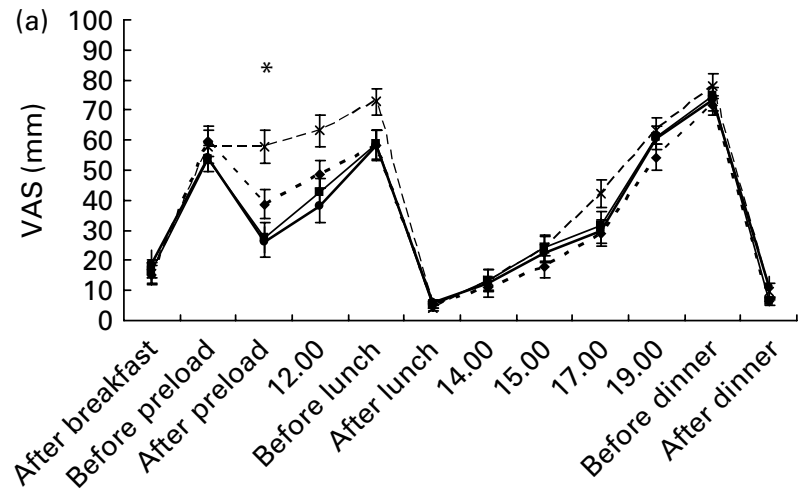

(b) 100
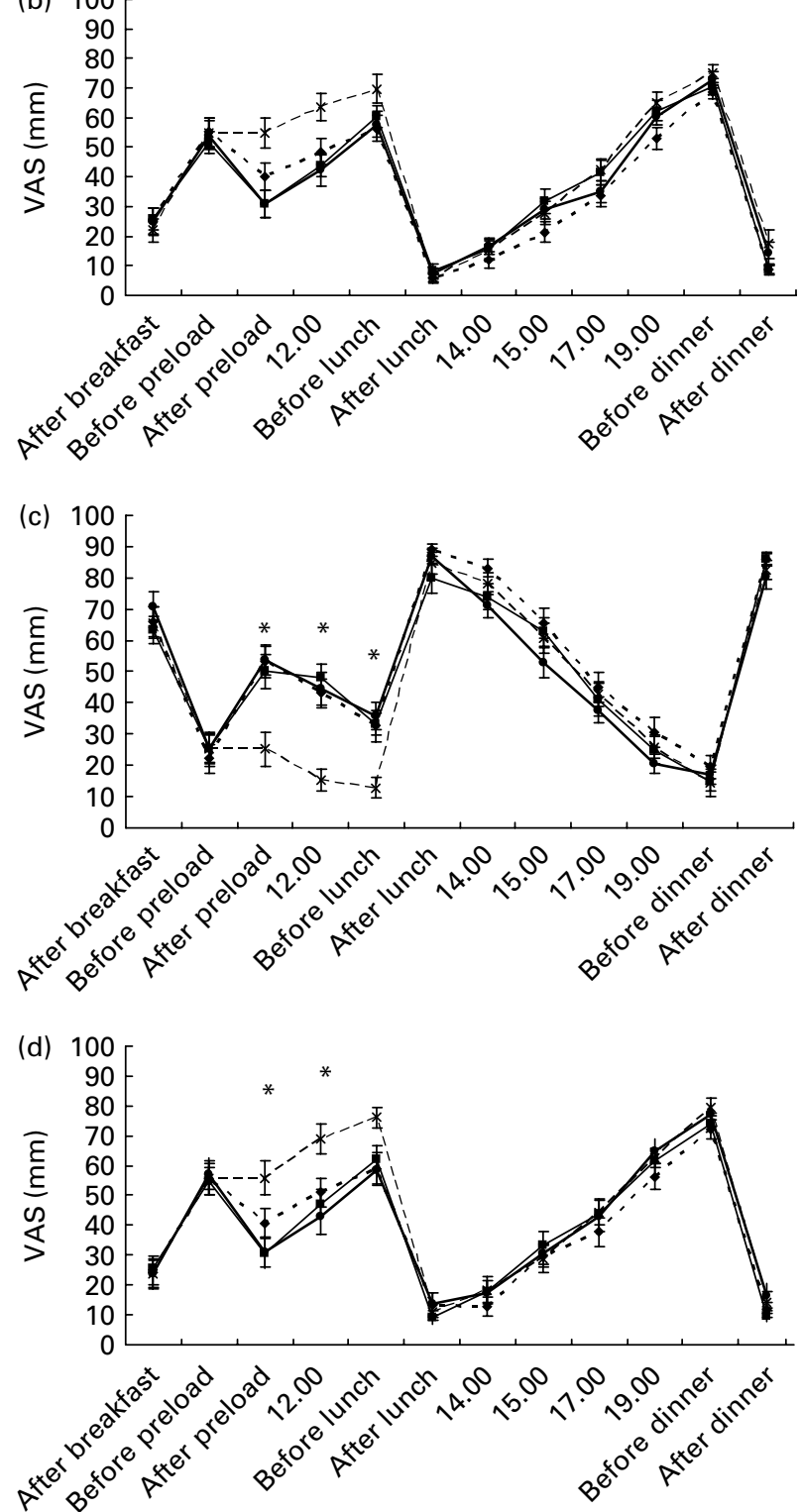

Fig. 3. (a) Hunger, (b) prospective food consumption, (c) fullness and (d) desire to eat scores rated by visual analogue scales (VAS) throughout the day in group T1 (group of volunteers who ate their lunch $1 \mathrm{~h}$ after ingesting the preload, $n$ 28). Values are means $(\mathrm{mm})$ with their standard errors. * Mean VAS scores were significantly different from the control with at least one of the three preloads $(P<0.05)$. $-\downarrow-$, Protein; $-\square-$, carbohydrates; - - lipids; $-\times-$, control. disappeared after lunch, and the evolution of appetite sensations remained the same thereafter under the four conditions (three preloads and control) (Fig. 2).

When the effect of ingesting the preloads was compared with the control in group T1, differences were only observed just after the ingestion of the preload, at 12.00 hours and before lunch. After ingesting the preload, hunger and desire to eat decreased significantly with the carbohydrate preload $(P=0.02$ and 0.008 , respectively) and the lipid preload $(P=0.007$ and 0.01 , respectively) compared with the control. Fullness was significantly higher compared with the control, whatever the preload ingested was $(P=0.001,0.01$ and 0.001 for proteins, carbohydrates and lipids, respectively). At 12.00 hours, fullness was significantly higher compared with the control, whatever the preload ingested was $(P=0.002,<0.001$ and 0.001 for proteins, carbohydrates and lipids, respectively). Desire to eat only decreased significantly with the lipid preload $(P=0.004)$. Before lunch, fullness was only significantly higher with the lipid preload $(P=0.03)$ compared with the control. These differences disappeared after lunch, and the evolution of appetite sensations remained the same thereafter under the four conditions (three preloads and control) (Fig. 3).

\section{Discussion}

The purpose of this study was to compare the effects of proteins, carbohydrates and lipids on appetite scores and food intake at subsequent meal(s) using preloads that only contained one of the three macronutrients. In this work, disguised preloads with the same volume, energy content, energy density, viscosity and palatability were used, because it had been shown that all these properties of food may affect food intake. In addition, the interval between the preload and test meal ingestion was also tested, as this also appeared to be an important parameter.

The main results showed that the ingestion of a preload before a test meal led to a decrease in energy intake at that meal and over the whole day. Throughout the day, when the energy of the preloads was included, food intake was higher after the ingestion of the lipid preload than in the control situation. Finally, there was neither any significant effect of the delay between the preload and test meal ingestion nor any interaction between preload and delay.

The present results are in agreement with the findings of several studies which showed that the consumption of a preload leads to a decrease in food intake at a test meal and/or appetite scores when compared with a control situation involving no preload. Indeed, Rolls et al. ${ }^{(35)}$ showed that volunteers displayed a lower energy intake during a test meal served $30 \mathrm{~min}$ after a high-carbohydrate yoghourt preload ingestion. Moreover, Kirkmeyer ${ }^{(36)}$ showed that hunger scores were lower $3 \mathrm{~h}$ after a $3 \mathrm{MJ}$ preload ingestion in comparison with the control situation.

In our study, the consumption of a preload led to a decrease in food intake compared with the control at lunch and over the whole day (energy of the preloads not included). Moreover, there was no difference between the three preloads except at lunch where energy intake after lipid ingestion was higher than that after carbohydrate ingestion. When the energy of the preloads was included, food intake was higher than that 
in the control situation after the ingestion of the three preloads at lunch and only after the ingestion of lipid preloads throughout the day. Energy compensation was partial at lunch and throughout the day except the $24 \mathrm{~h}$ energy compensation after the ingestion of a carbohydrate preload, which was not statistically different from $100 \%$. Moreover, the values of energy compensation did not differ between the three macronutrients.

With respect to VAS scores, we were not able to determine a difference between the three types of preloads. The responses of volunteers to the four questions on hunger, fullness, prospective food consumption and desire to eat were consistent with their intake: for instance, in group T0, the volunteers stated that they were hungrier just before lunch in the control situation than on days when they consumed a preload. In the same way, in group $\mathrm{T} 1$, the subjects stated that they were always hungrier between the time of the preload and lunch ingestion (after the ingestion of the preload, at 12.00 hours and before lunch) in the control situation than on days when they also consumed a preload.

The fact that we were not able to demonstrate any major differences between the effects of carbohydrates, proteins and lipids on food intake and appetite scores was in agreement with the findings of Geliebter ${ }^{(16)}$, who used isoenergetic liquid preloads of $1180 \mathrm{~kJ}$ containing either carbohydrates, proteins or lipids which were given $70 \mathrm{~min}$ before a test meal. In the same way, Fischer ${ }^{(26)}$ could not demonstrate a differential impact on food intake and appetite scores in a study using pure carbohydrate, protein or lipid vanilla cream preloads served $4 \mathrm{~h}$ before a test meal. Compared with these two studies and the present study, other experiments that revealed a hierarchy of satiety effects between macronutrients often used preloads which differed in terms of energy density, texture and palatability. For instance, Marmonier et al. ${ }^{(37)}$ compared the effects of a high-protein preload (chicken breast), high-fat preload (cream cheese) and high-carbohydrate preload (rye bread with raisins) by measuring the time elapsing between ingestion of the preload and the test meal based on spontaneous request, and showed that this period was significantly longer after the ingestion of a high-protein preload. Similarly, Rolls et al. ${ }^{(38)}$ showed that energy intake during a buffet meal was significantly lower $2 \mathrm{~h}$ after the ingestion of a preload rich in starch or proteins than after the ingestion of lipid or sucrose preloads, but these preloads were not disguised, and they differed markedly in terms of texture, energy density and palatability (pasta for the starch preload, chicken breast for the protein preload, cream cheese for the lipid preload and Turkish cakes for the sucrose preload). However, the sensory differences between preloads do not appear as an absolute necessity as shown by the work of Bertenshaw et al. ${ }^{(5)}$, which demonstrated a higher satiety of proteins than of carbohydrates consumed in disguised liquid preloads.

The pattern of differences between the effects of carbohydrates, proteins and lipids on food intake may have been due to the type of macronutrients used during our experiment. It has been shown that within a group of macronutrients, the type and source of proteins, carbohydrates or lipids may impact their satiety effect. In terms of proteins, differences have been demonstrated between egg and whey proteins ${ }^{(28)}$, and between casein and whey proteins ${ }^{(39)}$. As for carbohydrates, some studies have revealed differences between glucose and fructose ${ }^{(40)}$ or between low- and high-glycaemic index foods ${ }^{(41)}$. Rolls et al. ${ }^{(38)}$ also showed a difference in satiety effect between two types of carbohydrate preloads (starch and sucrose). Finally, in his review, French ${ }^{(42)}$ explained that chain length and the degree of fat saturation could have an influence on the satiety effect of lipids. In our study, we used certain types of carbohydrates (maltodextrins), proteins (90\% whey proteins and $10 \%$ casein) and lipids (50\% palm oil and $50 \%$ soya bean oil), which could explain the present results.

Other parameters may also explain the differences in results between studies, such as the amount of energy in preloads and the interval elapsing between the preload and test meal ingestion. Most studies that showed an effect of preloads on subsequent food intake used high-energy preloads containing between 1.5 and $3.0 \mathrm{MJ}^{(38,43)}$, which is somewhat higher than the value in our preloads $(1020 \mathrm{~kJ})$. However, the amount of energy supplied in our experiment appeared to be adequate because Marmonier et al. ${ }^{(37)}$ and Porrini et $a l{ }^{(14)}$ managed to demonstrate differential effects between macronutrients providing less energy. In our case, an interval of 0 or $1 \mathrm{~h}$ between the preload and test meal ingestion appeared to be appropriate, insofar as the studies done by Porrini et al. ${ }^{(14)}$ and Anderson et al. ${ }^{(28)}$ were able to demonstrate the satiety effect of a preload on a test meal eaten $0-120 \mathrm{~min}$ after its ingestion. However, we observed no difference between the two time intervals we used. Nevertheless, we could hypothesise that the maximum impact exerted by each macronutrient on satiety did not necessarily appear after the same period, and could also vary as a function of the physical appearance, or solid/liquid nature, of the foods tested.

The experiment was performed using normal-weight subjects because the aim was to study the effect of macronutrients on satiety under conditions that were as standardised as possible: healthy subjects, with no weight management problems and no diabetes or elevated cholesterol. However, our sample of volunteers included more women than men. Rolls et al. ${ }^{(35)}$ showed that young men appear to present better energy compensation after ingesting a preload than women. In our case, the results were the same for women analysed separately and for all the volunteers, whereas in men, we did not observe any decrease in food intake at lunch after they had ingested a preload. However, twelve men were included in the study, so the power of calculations concerning them was probably too weak to reach any clear conclusion.

Finally, it is possible to hypothesise that the perceptions of the volunteers with respect to the foods chosen as preloads may have influenced their food intake and appetite scores. Indeed, most studies that demonstrated any differences between macronutrients used solid preloads consisting of common foods ${ }^{(14,37,38)}$, whereas studies that did not reveal any differences between macronutrients used liquid or semiliquid preloads prepared specifically for the experiment and thus new to the subjects ${ }^{(16,44)}$. Moreover, most studies that demonstrated a satiety effect of liquids used soups, which tend to be perceived as a meal as opposed to juice or sweetened drinks ${ }^{(29,45)}$. In our study, we used sweet chocolate drinks previously unknown to the volunteers, which they may not have considered as a real food. It could be suggested 
that using a novel food as a preload may influence its impact on food intake. According to the concept of learned satiety demonstrated by Louis-Sylvestre ${ }^{(46)}$, human subjects are able to learn and anticipate the consequences of ingesting a particular food after a short conditioning period on appetite sensations. The effect of discovering a novel food as a preload may mask the potential effect of the macronutrients. In view of this hypothesis, one suggestion concerning future studies may be to include, as it has been already carried out in works of Yeomans $^{(47)}$ and Booth ${ }^{(48)}$, a conditioning period of a few days for each type of preload before the test day in order to circumvent the 'novel food effect' and thus obtain an impact on food intake that is solely dependent on the macronutrient composition. It might also be possible to use disguised pure macronutrients in solid preloads, but this may constitute an unachievable technological challenge.

In conclusion, we were not able to confirm the stronger satiety effect of a liquid pure protein preload by comparison with carbohydrate or lipid preloads with the same energy content, energy density, viscosity and palatability, in healthy normal-weight men and women, following the first time they were consumed. However, some of our findings showed that a lipid preload does not lead to a reduction in food intake compared with a control situation, and that it leads to a higher energy intake than that observed after carbohydrate ingestion, thus suggesting a weaker satiety effect of lipids.

\section{Acknowledgements}

We confirm that no conflicts of interest are associated with the present study. The study received funding from INRA. We would also like to thank Anne Regourd and Pascale Reichl for their assistance in carrying out the protocol. The authors' contributions are as follows: M. P., A. M.-B., G. F. and D. T. designed the study and compiled the manuscript. A. L. and R. B. contributed to the design of the study.

\section{References}

1. Paddon-Jones D, Westman E, Mattes RD, et al. (2008) Protein, weight management, and satiety. Am J Clin Nutr 87, 1558S-1561S.

2. Hermsdorff HH, Volp AC \& Bressan J (2007) Macronutrient profile affects diet-induced thermogenesis and energy intake. Arch Latinoam Nutr 57, 33-42.

3. Westerterp-Plantenga MS (2003) The significance of protein in food intake and body weight regulation. Curr Opin Clin Nutr Metab Care 6, 635-638.

4. Doucet E \& Tremblay A (1997) Food intake, energy balance and body weight control. Eur J Clin Nutr 51, 846-855.

5. Bertenshaw EJ, Lluch A \& Yeomans MR (2008) Satiating effects of protein but not carbohydrate consumed in a between-meal beverage context. Physiol Behav 93, 427-436.

6. Leidy HJ, Bossingham MJ, Mattes RD, et al. (2009) Increased dietary protein consumed at breakfast leads to an initial and sustained feeling of fullness during energy restriction compared to other meal times. Br J Nutr 101, 798-803.

7. Gerstein DE, Woodward-Lopez G, Evans AE, et al. (2004) Clarifying concepts about macronutrients' effects on satiation and satiety. J Am Diet Assoc 104, 1151-1153.

8. Bensaid A, Tomé D, Gietzen D, et al. (2002) Protein is more potent than carbohydrate for reducing appetite in rats. Physiol Behav 75, 577-582.
9. Latner JD \& Schwartz M (1999) The effects of a highcarbohydrate, high-protein or balanced lunch upon later food intake and hunger ratings. Appetite 33, 119-128.

10. Dove ER, Hodgson JM, Puddey IB, et al. (2009) Skim milk compared with a fruit drink acutely reduces appetite and energy intake in overweight men and women. Am J Clin Nutr 90, 70-75.

11. Hochstenbach-Waelen A, Veldhorst MA, Nieuwenhuizen AG, et al. (2009) Comparison of 2 diets with either $25 \%$ or $10 \%$ of energy as casein on energy expenditure, substrate balance, and appetite profile. Am J Clin Nutr 89, 831-838.

12. Veldhorst MA, Nieuwenhuizen AG, Hochstenbach-Waelen A, et al. (2009) Effects of high and normal soyprotein breakfasts on satiety and subsequent energy intake, including amino acid and 'satiety' hormone responses. Eur J Nutr 48, 92-100.

13. Bertenshaw EJ, Lluch A \& Yeomans MR (2009) Dosedependent effects of beverage protein content upon short-term intake. Appetite 52, 580-587.

14. Porrini M, Santangelo A, Crovetti R, et al. (1997) Weight, protein, fat, and timing of preloads affect food intake. Physiol Behav 62, 563-570.

15. de Graaf C, Schreurs A \& Blauw YH (1993) Short-term effects of different amounts of sweet and nonsweet carbohydrates on satiety and energy intake. Physiol Behav 54, 833-843.

16. Geliebter AA (1979) Effects of equicaloric loads of protein, fat, and carbohydrate on food intake in the rat and man. Physiol Behav 22, 267-273.

17. Rolls BJ, Kim S, McNelis AL, et al. (1991) Time course of effects of preloads high in fat or carbohydrate on food intake and hunger ratings in humans. Am J Physiol 260, R756-R763.

18. Capaldi ED, Owens JQ \& Privitera GJ (2006) Isocaloric meal and snack foods differentially affect eating behavior. Appetite 46, 117-123.

19. Drewnowski A (1998) Energy density, palatability, and satiety: implications for weight control. Nutr Rev 56, 347-353.

20. Poppitt SD, McCormack D \& Buffenstein R (1998) Short-term effects of macronutrient preloads on appetite and energy intake in lean women. Physiol Behav 64, 279-285.

21. Mattes RD \& Rothacker D (2001) Beverage viscosity is inversely related to postprandial hunger in humans. Physiol Behav 74, 551-557.

22. Mattes RD (1996) Dietary compensation by humans for supplemental energy provided as ethanol or carbohydrate in fluids. Physiol Behav 59, 179-187.

23. DiMeglio DP \& Mattes RD (2000) Liquid versus solid carbohydrate: effects on food intake and body weight. Int $J$ Obes Relat Metab Disord 24, 794-800.

24. Booth DA, Chase A \& Campbell AT (1970) Relative effectiveness of protein in the late stages of appetite suppression in man. Physiol Behav 5, 1299-1302.

25. Booth DA \& Jarman SP (1976) Inhibition of food intake in the rat following complete absorption of glucose delivered into the stomach, intestine or liver. J Physiol 259, 501-522.

26. Fischer K, Colombani PC \& Wenk C (2004) Metabolic and cognitive coefficients in the development of hunger sensations after pure macronutrient ingestion in the morning. Appetite 42, 49-61.

27. Raben A, Agerholm-Larsen L, Flint A, et al. (2003) Meals with similar energy densities but rich in protein, fat, carbohydrate, or alcohol have different effects on energy expenditure and substrate metabolism but not on appetite and energy intake. Am J Clin Nutr 77, 91-100.

28. Anderson GH, Tecimer SN, Shah D, et al. (2004) Protein source, quantity, and time of consumption determine the effect of proteins on short-term food intake in young men. J Nutr 134, 3011-3015. 
29. Almiron-Roig E, Chen Y \& Drewnowski A (2003) Liquid calories and the failure of satiety: how good is the evidence? Obes Rev 4, 201-212.

30. Rolls BJ, Bell EA \& Thorwart ML (1999) Water incorporated into a food but not served with a food decreases energy intake in lean women. Am J Clin Nutr 70, 448-455.

31. Kissileff HR, Gruss LP, Thornton J, et al. (1984) The satiating efficiency of foods. Physiol Behav 32, 319-332.

32. Rolls BJ, Fedoroff IC, Guthrie JF, et al. (1990) Foods with different satiating effects in humans. Appetite 15, 115-126.

33. Himaya A \& Louis-Sylvestre J (1998) The effect of soup on satiation. Appetite 30, 199-210.

34. Stunkard AJ \& Messick S (1985) The three-factor eating questionnaire to measure dietary restraint, disinhibition and hunger. J Psychosom Res 29, 71-83.

35. Rolls BJ, Kim-Harris S, Fischman MW, et al. (1994) Satiety after preloads with different amounts of fat and carbohydrate: implications for obesity. Am J Clin Nutr 60, 476-487.

36. Kirkmeyer SV \& Mattes RD (2000) Effects of food attributes on hunger and food intake. Int $J$ Obes Relat Metab Disord 24, $1167-1175$.

37. Marmonier C, Chapelot D \& Louis-Sylvestre J (2000) Effects of macronutrient content and energy density of snacks consumed in a satiety state on the onset of the next meal. Appetite 34, 161-168.

38. Rolls BJ, Hetherington M \& Burley VJ (1988) The specificity of satiety: the influence of foods of different macronutrient content on the development of satiety. Physiol Behav 43, 145-153.
39. Hall WL, Millward DJ, Long SJ, et al. (2003) Casein and whey exert different effects on plasma amino acid profiles, gastrointestinal hormone secretion and appetite. Br J Nutr 89, 239-248.

40. Spitzer L \& Rodin J (1987) Effects of fructose and glucose preloads on subsequent food intake. Appetite 8, 135-145.

41. Raben A (2002) Should obese patients be counselled to follow a low-glycaemic index diet? No. Obes Rev 3, 245-256.

42. French S (2004) Effects of dietary fat and carbohydrate on appetite vary depending upon site and structure. Br J Nutr 92, Suppl. 1, S23-S26.

43. Whybrow S, Mayer C, Kirk TR, et al. (2007) Effects of two weeks' mandatory snack consumption on energy intake and energy balance. Obesity (Silver Spring) 15, 673-685.

44. de Graaf C, Hulshof T, Weststrate JA, et al. (1992) Short-term effects of different amounts of protein, fats, and carbohydrates on satiety. Am J Clin Nutr 55, 33-38.

45. Mattes R (2005) Soup and satiety. Physiol Behav 83, 739-747.

46. Louis-Sylvestre J, Tournier A, Verger P, et al. (1989) Learned caloric adjustment of human intake. Appetite 12, 95-103.

47. Yeomans MR, Gould NJ, Leitch M, et al. (2009) Effects of energy density and portion size on development of acquired flavour liking and learned satiety. Appetite 52, 469-478.

48. Booth DA, Mather P \& Fuller J (1982) Starch content of ordinary foods associatively conditions human appetite and satiation, indexed by intake and eating pleasantness of starch-paired flavours. Appetite 3, 163-184. 